\title{
Transpulmonary thermodilution detects rapid and reversible increases in lung water induced by positive end-expiratory pressure in acute respiratory distress syndrome
}

Francesco Gavelli1 ${ }^{1,23^{*}}$ D, Jean-Louis Teboul ${ }^{1,2}$, Danila Azzolina ${ }^{3}$, Alexandra Beurton ${ }^{1,2}$, Temistocle Taccheri ${ }^{1,2}$, Imane Adda ${ }^{1,2}$, Christopher Lai ${ }^{1,2}$, Gian Carlo Avanzi ${ }^{3}$ and Xavier Monnet ${ }^{1,2}$

\begin{abstract}
Purpose: It has been suggested that, by recruiting lung regions and enlarging the distribution volume of the cold indicator, increasing the positive end-expiratory pressure (PEEP) may lead to an artefactual overestimation of extravascular lung water (EVLW) by transpulmonary thermodilution (TPTD).

Methods: In 60 ARDS patients, we measured EVLW (PiCCO2 device) at a PEEP level set to reach a plateau pressure of $30 \mathrm{cmH}_{2} \mathrm{O}\left(\mathrm{HighPEEP}_{\text {start }}\right)$ and 15 and 45 min after decreasing PEEP to $5 \mathrm{cmH}_{2} \mathrm{O}$ (LowPEEP ${ }_{15^{\prime}}$ and LowPEEP (5, $^{\prime}$, respectively). Then, we increased PEEP back to the baseline level (HighPEEP end). Between HighPEEP start $_{\text {and }}$ LowPEEP ${ }_{15}$, we estimated the degree of lung derecruitment either by measuring changes in the compliance of the respiratory system (Crs) in the whole population, or by measuring the lung derecruited volume in 30 patients. We defined patients with a large derecruitment from the other ones as patients in whom the Crs changes and the measured derecruited volume were larger than the median of these variables observed in the whole population.

Results: Reducing PEEP from HighPEEP start $\left(14 \pm 2 \mathrm{cmH}_{2} \mathrm{O}\right)$ to LoWPEEP ${ }_{15}$, significantly decreased EVLW from $20 \pm 4$ to $18 \pm 4 \mathrm{~mL} / \mathrm{kg}$, central venous pressure (CVP) from $15 \pm 4$ to $12 \pm 4 \mathrm{mmHg}$, the arterial oxygen tension over inspired oxygen fraction $\left(\mathrm{PaO}_{2} / \mathrm{FiO}_{2}\right)$ ratio from $184 \pm 76$ to $150 \pm 69 \mathrm{mmHg}$ and lung volume by 144 [68-420] $\mathrm{mL}$. The EVLW decrease was similar in "large derecruiters" and the other patients. When PEEP was re-increased to HighPEEP end, CVP, $\mathrm{PaO}_{2} / \mathrm{FiO}_{2}$ and EVLW significantly re-increased. At linear mixed effect model, EVLW changes were significantly determined only by changes in PEEP and CVP $(p<0.001$ and $p=0.03$, respectively, $n=60)$. When the same analysis was performed by estimating recruitment according to lung volume changes $(n=30)$, CVP remained significantly associated to the changes in EVLW $(p<0.001)$.

Conclusions: In ARDS patients, changing the PEEP level induced parallel, small and reversible changes in EVLW. These changes were not due to an artefact of the TPTD technique and were likely due to the PEEP-induced changes in CVP, which is the backward pressure of the lung lymphatic drainage.

Trial registration ID RCB: 2015-A01654-45. Registered 23 October 2015
\end{abstract}

\footnotetext{
*Correspondence: francesco.gavelli@uniupo.it

1 Service de médecine intensive - réanimation, Hôpitaux universitaires

Paris-Saclay, Hôpital de Bicêtre, APHP, 78, rue du Général Leclerc, 94270 Le

Kremlin-Bicêtre, France

Full list of author information is available at the end of the article
} adaptation, distribution and reproduction in any medium or format, as long as you give appropriate credit to the original author(s) and the source, provide a link to the Creative Commons licence, and indicate if changes were made. The images or other third party material in this article are included in the article's Creative Commons licence, unless indicated otherwise in a credit line to the material. If material is not included in the article's Creative Commons licence and your intended use is not permitted by statutory regulation or exceeds the permitted use, you will need to obtain permission directly from the copyright holder. To view a copy of this licence, visit http://creativeco mmons.org/licenses/by/4.0/. 
Keywords: Pulmonary oedema, Pulmonary lymphatic drainage, Central venous pressure, Lung recruitment, Mechanical ventilation

\section{Background}

Extravascular lung water (EVLW) is the amount of fluid present in the lungs, outside the pulmonary blood vessels [1]. In acute respiratory distress syndrome (ARDS), lung injury leads to increases in the pulmonary capillary permeability and in EVLW, which reflect the severity of the disease [2].

Many studies have investigated the changes in EVLW induced by a positive end-expiratory pressure (PEEP), which is the cornerstone of ARDS treatment (Additional file 1: Table S1). However, they have provided very discordant results, some showing that EVLW augmented when increasing levels of PEEP were applied [3-8], some that it decreased [9-17] and some others that it did not change [18-28].

The large majority of these studies were conducted in animals [3-5, 8-27], with various models of ARDS and methods of EVLW estimation. Today, the routine measurement of EVLW at the bedside is allowed by transpulmonary thermodilution (TPTD). One animal [8] and three human studies $[6,7,28]$ have investigated the effects of PEEP changes on TPTD-estimated EVLW, three suggesting that EVLW increases with PEEP [6-8] and another one that it remains unchanged [28]. However, these studies did not investigate the potential artefact that may induce an increase in EVLW along with the PEEP level.

Indeed, the PEEP-induced lung recruitment may relieve the hypoxic vasoconstriction of the recruited regions, which eventually become accessible to the cold indicator while they were not at a lower PEEP level. This may lead to an artefactual overestimation of the PEEPinduced EVLW augmentation.

Thus, the goal of our study, conducted in ARDS patients, was to investigate whether the estimation of EVLW by TPTD is artefactually influenced by the lung derecruitment potentially secondary to the decrease in the PEEP level.

\section{Methods}

\section{Patients}

This prospective, one-centre study was approved by the Institutional Review Board of our institution (Comité pour la Protection des Personnes, Ile-de-France VII, IDCRB 2015-A01654-45). At the time of inclusion, patients' relatives were informed of the study protocol and possibility was given to them to refuse participation. As soon as clinical condition improved and patients were able to give consent, the same information was delivered to them, with possibility for them to deny the participation. All patients and/or relatives accepted to participate.

Inclusion criteria were age $\geq 18$ years, presence of ARDS according to the Berlin definition [29] and monitoring with a TPTD device (PiCCO2 device, Pulsion Medical Systems, Feldkirchen, Germany). Exclusion criteria were contraindications to PEEP increase (pneumothorax, uncontrolled shock state) and extracorporeal membrane oxygenation, which impedes the measurement of EVLW by TPTD. Patients could be under continuous venovenous haemofiltration since it does not affect the TPTD estimation of EVLW [30,31].

\section{TPTD measurements}

TPTD measurements were performed by injecting 15 -mL boluses of saline $\left(<8{ }^{\circ} \mathrm{C}\right)$ through a jugular vein catheter. In order to allow the detection of small changes in EVLW, the average of the results obtained by five successive thermodilution measurements was used. With this number of replicates, the least significant change of EVLW is 8\% [32].

With TPTD, we also measured the pulmonary vascular permeability index (PVPI) [1,33] (also averaged from five successive thermodilution measurements) and cardiac index $(\mathrm{CI})$.

\section{Haemodynamic measurements}

In addition to arterial pressure and $\mathrm{CI}$, we measured the central venous pressure (CVP) at the base of the $C$ wave, at end-expiration. The value of three successive respiratory cycles was averaged. The pressure transducer was attached to the arm, at a height corresponding to the level of the right atrium.

\section{Estimation of alveolar derecruitment induced by PEEP decreases}

In a subgroup of 30 patients ventilated with an Infinity V500 ventilator (Dräger, Lübeck, Germany), we directly estimated the volume of derecruited lung during the PEEP decrease. For this purpose, after transiently reducing the respiratory rate to 10 breaths/min to reduce the risk of air trapping, a prolonged expiration was performed while abruptly reducing PEEP from its baseline value to $5 \mathrm{cmH}_{2} \mathrm{O}$ for one breath. The difference in end-expiratory Vt between the breath while PEEP was decreased and the one before was defined as the total change in lung volume [34]. At the same time, we 
estimated the minimal predicted change in lung volume determined by the PEEP change, as previously described [35]. Briefly, the respiratory system compliance at low PEEP was multiplied by the pressure difference between the two PEEP levels. Then, this value was subtracted from the total change in lung volume and the result was considered as an estimation of derecruited lung volume induced by PEEP reduction $[34,35]$. In addition, in the whole population, we estimated the degree of derecruitment during the PEEP decrease by observing the simultaneous changes in compliance of the respiratory system (Crs) [36]. For this purpose, Crs was calculated as the ratio of tidal volume $(\mathrm{Vt})$ over the driving pressure (plateau pressure-PEEP).

We defined patients with a large derecruitment from the other ones as patients in whom Crs changes and the measured derecruited volume were larger than the median of their value observed in the whole population.

\section{Study design}

At baseline, patients were ventilated in the assist-control mode with a Vt at $6 \mathrm{~mL} / \mathrm{kg}$ (predicted body weight). PEEP was set to reach a plateau pressure of $28-30 \mathrm{cmH}_{2} \mathrm{O}$ (High-PEEP) [37]. Sedation was provided by propofol and remifentanil.

At this time (High-PEEP start $_{\text {) }}$ a first set of measurements was performed including heart rate, arterial pressure, CVP, EVLW and blood gas analysis. PEEP was then decreased, while the derecruited volume was estimated in the 30 patients in whom it was possible. After $15 \mathrm{~min}$ (Low-PEEP ${ }_{15^{\prime}}$ ) and 45 min (Low-PEEP ${ }_{45^{\prime}}$ ), we measured the same variables as at baseline. A time interval of $45 \mathrm{~min}$ appeared to us as reasonably long enough for allowing potential fluid transfer through the pulmonary capillary barrier. Thereafter, PEEP was increased back to its baseline level. After $15 \mathrm{~min}$, the variables measured at baseline were measured again (High-PEEP ${ }_{\text {end }}$ ).

Sedative drugs, Vt, respiratory rate, and the fraction of inspired oxygen $\left(\mathrm{FiO}_{2}\right)$ remained unchanged during the study. Volume expansion, fluid removal, recruitment manoeuvres, administration of inhaled nitric oxide or nebulization were not performed during this time.

\section{Statistical analysis}

Considering an $\alpha$ risk of $5 \%$ and a $\beta$ risk of $20 \%$, to evidence a PEEP-induced change in EVLW by $2 \pm 4 \mathrm{~mL} / \mathrm{kg}$, we estimated that 54 patients should be included into the study, a number that was rounded to 60 . The PEEPinduced change in EVLW was estimated by considering that the least significant change of the measurement is $8 \%$ if five values of TPTD are averaged [32] and by expecting a baseline EVLW of $20 \pm 6 \mathrm{~mL} / \mathrm{kg}$ [38].
Data are expressed as mean \pm standard deviation for normally distributed variables or median [interquartile range] for skewed data. A Shapiro-Wilk test was considered to determine if a variable was well-modelled by a normal distribution. The analysis of patients with a large derecruitment compared to the other ones was planned a priori.

A linear mixed factor ANOVA for repeated measurements was used to evaluate both within-subject effect (PEEP/time effect) and between-subject effects (recruiting effect). Both High-PEEP start $_{\text {and Low- }}$ PEEP $_{45^{\prime}}$ have been considered as reference categories for comparisons. Multiple comparisons of means have been performed using Tukey contrasts.

The covariate effect on EVLW outcome was then estimated using a linear mixed model for repeated measurements (random intercept model) adjusting the estimates for PEEP, position (prone/supine) and recruiting effect according either to the Crs changes and the recruited lung volume. Sample size calculation and statistical analysis were performed with MedCalc 18.2.1 software (Mariakerke, Belgium) and R 3.5.2 statistical software with lme4 package.

\section{Results \\ Patients}

Sixty consecutive patients were included. On average, ARDS developed for 3 [1-5] days at the time of inclusion. Septic shock was present in 54 (90\%) patients (Table 1). Pneumonia was the cause of ARDS in all patients. The number of chest X-ray quadrants involved was two in $21(35 \%)$ cases, three in $35(58 \%)$ cases and four in $4(7 \%)$ patients. At baseline, blood lactate was $2.5[1.6-3.4] \mathrm{mmol} / \mathrm{L}$, creatinine 98 [66-106] $\mu \mathrm{mol} / \mathrm{L}$ and $15(25 \%)$ patients had renal replacement therapy in place (conventional haemodialysis in three, continuous venovenous hemofiltration in 12 patients, without weight loss). Eleven (18\%) patients were in prone position at the time of inclusion, whereas 28 (47\%) other ones had required prone positioning before the inclusion (Table 1). Seventeen (28\%) patients were paralysed at the time of inclusion and the Richmond AgitationSedation Scale was -4 [ -5 to -3$]$.

\section{Effects of PEEP changes on haemodynamic variables}

The decrease in PEEP from High-PEEP start decreased CVP by $21 \pm 13 \%(p<0.01)$ (Table 2$)$. When PEEP was increased from Low-PEEP $45^{\prime}$ to High-PEEP end , opposite and symmetrical changes were observed (Table 2; see Additional file 2: Table S2 for post hoc comparisons). 


\section{Table 1 Patient characteristics}

\begin{tabular}{|c|c|}
\hline \multicolumn{2}{|l|}{ Patient characteristics ( $n=60)$} \\
\hline Age (years) & $69 \pm 10$ \\
\hline Male gender $(n, \%)$ & $34(57 \%)$ \\
\hline Body mass index $\left(\mathrm{kg} / \mathrm{m}^{2}\right)$ & $25 \pm 4$ \\
\hline Simplified Acute Physiologic Score II on inclusion & $51 \pm 18$ \\
\hline \multicolumn{2}{|l|}{ ARDS severity $(n, \%)$} \\
\hline Mild & $21(35 \%)$ \\
\hline Moderate & $31(52 \%)$ \\
\hline Severe & $8(13 \%)$ \\
\hline \multicolumn{2}{|l|}{ Aetiology of ARDS ( $n, \%)$} \\
\hline Community acquired pneumonia & $46(77 \%)$ \\
\hline Aspiration pneumonia with neurologic disorders & $5(8 \%)$ \\
\hline Ventilator associated pneumonia & $9(15 \%)$ \\
\hline ICU length of stay (days) & $12[11-38]$ \\
\hline Total duration of mechanical ventilation (days) & $11[10-37]$ \\
\hline Mortality at day-28 (n, \%) & $26(43 \%)$ \\
\hline \multicolumn{2}{|l|}{ Norepinephrine } \\
\hline Number of patients (\%) & $54(90 \%)$ \\
\hline Dose of norepinephrine $(\mu \mathrm{g} / \mathrm{kg} / \mathrm{min})$ & $0.53[0.27-1.00]$ \\
\hline Left ventricular ejection fraction (\%) & $44 \pm 11$ \\
\hline E/e' ratio & $9 \pm 2$ \\
\hline \multicolumn{2}{|l|}{ Ventilator settings } \\
\hline Tidal volume (mL/kg of PBW) & $5.5[5.0-6.0]$ \\
\hline Respiratory rate (breaths/min) & $27 \pm 5$ \\
\hline Fraction of inspired oxygen & $0.64 \pm 0.20$ \\
\hline Patients requiring prone position $(n, \%)$ & $39(65 \%)$ \\
\hline
\end{tabular}

ARDS: acute respiratory distress syndrome; $E / e^{\prime}$ : ratio of the amplitude of the $E$ wave over the amplitude of the $e^{\prime}$ wave of the mitral flow with echocardiography; ICU: intensive care unit; PBW: predicted body weight

\section{Effects of PEEP changes on respiratory variables} From High-PEEP start $_{\text {to }}$ Low-PEEP ${ }_{15}$, PEEP decreased by $9 \pm 2 \mathrm{cmH}_{2} \mathrm{O}$ and this was accompanied by a decrease in the plateau pressure by $8 \pm 3 \mathrm{cmH}_{2} \mathrm{O}$. When decreasing PEEP from High-PEEP ${ }_{\text {start }}$, the change in Crs was $0.0[-3.8$ to 3.8$] \mathrm{mL} / \mathrm{cmH}_{2} \mathrm{O}(n=60)$ (Table 2). Since the median value of Crs changes was $0.0 \mathrm{~mL} /$ $\mathrm{cmH}_{2} \mathrm{O}$, we defined derecruiters as patients in whom decreasing PEEP induced a decrease in Crs. When decreasing PEEP from High-PEEP ${ }_{\text {start }}$ the estimated derecruited lung volume was $144[68-420] \mathrm{mL}$ in the patients in whom it was measured $(n=30)$.

No differences were found in terms of EVLW changes between derecruiters and the other patients, defined according to either the Crs change $(n=60)$ or the derecruited volume $(n=30)$. All the significant changes in respiratory variables reversed with a similar amplitude when PEEP was increased from Low-PEEP ${ }_{45}$ to High$\operatorname{PEEP}_{\text {end }}$ (Table 2).

\section{Effects of PEEP changes on EVLW}

Decreasing PEEP from High-PEEP start $_{\text {induced a sig- }}$ nificant decrease in EVLW by $8 \pm 7 \%(p<0.01)$ (Table 2, Fig. 1). This decrease in EVLW was observed in all the patients but two (Fig. 1). It persisted at Low-PEEP ${ }_{15}$ and Low-PEEP ${ }_{45}$. When PEEP was increased from LowPEEP $_{45^{\prime}}$ to High-PEEP ${ }_{\text {end }}$, opposite and symmetrical changes in EVLW were observed (Table 2).

When we evaluated the covariate effect on EVLW at the linear mixed model for repeated measures, adjusted for PEEP, prone/supine position and recruitment according to Crs changes, only the changes in PEEP and CVP were significantly associated to the changes in EVLW $(p<0.001$ and $p=0.03$, respectively) (Table 3$)$. When we performed the same analysis by estimating recruitment according to lung volume changes $(n=30)$, CVP but not the recruited lung volume remained significantly associated to the changes in EVLW $(p<0.001)$.

\section{Discussion}

This study shows that decreasing PEEP in ARDS patients induces a small, reversible and rapid decrease in EVLW measured by TPTD. The recruited lung volume was not independently associated with this change in EVLW, while it was the case for the change in CVP.

\section{Were the PEEP-induced changes in EVLW due to artefacts of the TPTD technique?}

At the bedside, the only technique that allows the measurement of EVLW is TPTD. Although it can detect interstitial oedema, lung ultrasound does not allow the quantification of the EVLW total volume, and CT scan cannot be used routinely. The estimation of EVLW by TPTD in humans has been demonstrated to correlate with the one provided by gravimetry [39], which is the reference technique. Even small and rapid changes in EVLW can be measured [40]. The value of EVLW has been regularly demonstrated to be correlated with mortality in critically ill patients $[41,42]$, especially in septic shock [43, 44] and ARDS [38, 45].

Nevertheless, the ability of TPTD to assess the changes in EVLW induced by PEEP has been only scarcely investigated, despite its important role in ARDS management [46]. Moreover, the few available studies did not specifically investigate the artefact that may affect the TPTD estimation of PEEP-induced changes in EVLW [6-8, 28]. As a matter of fact, by relieving the hypoxic vasoconstriction in recruited areas, PEEP may allow the cold indicator to reach these regions, increasing the volume of EVLW that is accessible to measurement. In our study, the changes in EVLW were the same among patients with high or low derecruitment, when derecruitment 
Table 2 Haemodynamic and respiratory variables

\begin{tabular}{|c|c|c|c|c|}
\hline Variables & High-PEEP $_{\text {start }}$ & Low-PEEP $_{15^{\prime}}$ & Low-PEEP ${ }_{45^{\prime}}$ & High-PEEP \\
\hline Heart rate $\left(\mathrm{min}^{-1}\right)$ & $89 \pm 18$ & $90 \pm 19$ & $91 \pm 19$ & $91 \pm 19$ \\
\hline Systolic arterial pressure $(\mathrm{mmHg})$ & $130 \pm 25$ & $132 \pm 19$ & $129 \pm 19$ & $124 \pm 17$ \\
\hline Diastolic arterial pressure $(\mathrm{mmHg})$ & $65 \pm 20$ & $63 \pm 10$ & $62 \pm 11$ & $62 \pm 10$ \\
\hline Mean arterial pressure $(\mathrm{mmHg})$ & $86 \pm 16$ & $86 \pm 13$ & $85 \pm 14$ & $83 \pm 11$ \\
\hline Central venous pressure $(\mathrm{mmHg})$ & $15 \pm 4$ & $12 \pm 4^{*}$ & $12 \pm 4^{*}$ & $15 \pm 4^{* *}$ \\
\hline Cardiac index $\left(\mathrm{L} / \mathrm{min} / \mathrm{m}^{2}\right)$ & $2.77 \pm 0.79$ & $3.08 \pm 0.85^{*}$ & $3.12 \pm 0.90^{*}$ & $2.81 \pm 0.89^{* *}$ \\
\hline Cardiac function index $\left(\mathrm{min}^{-1}\right)$ & $4.0 \pm 1.2$ & $4.3 \pm 1.3^{*}$ & $4.3 \pm 1.3^{*}$ & $4.1 \pm 1.3^{* *}$ \\
\hline Global end-diastolic volume indexed $\left(\mathrm{mL} / \mathrm{m}^{2}\right)$ & $750 \pm 116$ & $787 \pm 168^{*}$ & $791 \pm 150^{*}$ & $748 \pm 127^{* *}$ \\
\hline Extravascular lung water (mL/kg) & $20 \pm 4$ & $18 \pm 4^{*}$ & $18 \pm 4^{*}$ & $20 \pm 5^{* *}$ \\
\hline Pulmonary vascular permeability index & $3.6 \pm 1.0$ & $3.5 \pm 1.0^{*}$ & $3.5 \pm 1.0^{*}$ & $3.6 \pm 0.9$ \\
\hline Pulse pressure variation (\%) & $7[4-14]$ & $6[4-12]$ & $8[4-12]$ & $7[5-11]$ \\
\hline Stroke volume variation (\%) & $8[5-13]$ & $7[4-13]$ & $7[5-13]$ & $8[6-13]$ \\
\hline $\operatorname{PEEP}\left(\mathrm{cmH}_{2} \mathrm{O}\right)$ & $14 \pm 2$ & $5 \pm 0^{*}$ & $5 \pm 0^{*}$ & $14 \pm 2^{* *}$ \\
\hline Pplateau $\left(\mathrm{cmH}_{2} \mathrm{O}\right)$ & $28 \pm 2$ & $20 \pm 3^{*}$ & $20 \pm 3^{*}$ & $28 \pm 2^{* *}$ \\
\hline Respiratory system compliance $\left(\mathrm{mL} / \mathrm{cmH}_{2} \mathrm{O}\right)$ & $27[22-32]$ & $26[24-28]$ & $25[23-28]$ & $27[23-31]$ \\
\hline $\mathrm{SpO}_{2}(\%)$ & $98 \pm 2$ & $96 \pm 3^{*}$ & $95 \pm 4^{*}$ & $98 \pm 2^{* *}$ \\
\hline $\mathrm{SaO}_{2}(\%)$ & $97 \pm 3$ & $94 \pm 5^{*}$ & $93 \pm 6+^{*}$ & $96 \pm 4^{* *}$ \\
\hline $\mathrm{PaO}_{2} / \mathrm{FiO}_{2}$ ratio & $184 \pm 76$ & $150 \pm 69^{*}$ & $147 \pm 68^{*}$ & $178 \pm 76^{* *}$ \\
\hline
\end{tabular}

$\mathrm{FiO}_{2}$ inspired oxygen fraction, $\mathrm{PEEP}$ positive end-expiratory pressure, Pplateau plateau pressure, $\mathrm{PaO}_{2}$ arterial oxygen partial pressure, $\mathrm{SaO}_{2}$ arterial oxygen saturation, $\mathrm{SpO}_{2}$ pulse oxygen saturation

${ }^{*} p<0.05$ vs. High-PEEP start $^{* *} p<0.05$ vs. Low-PEEP ${ }_{45}$. See Additional file 2: Table S2 for post hoc comparisons

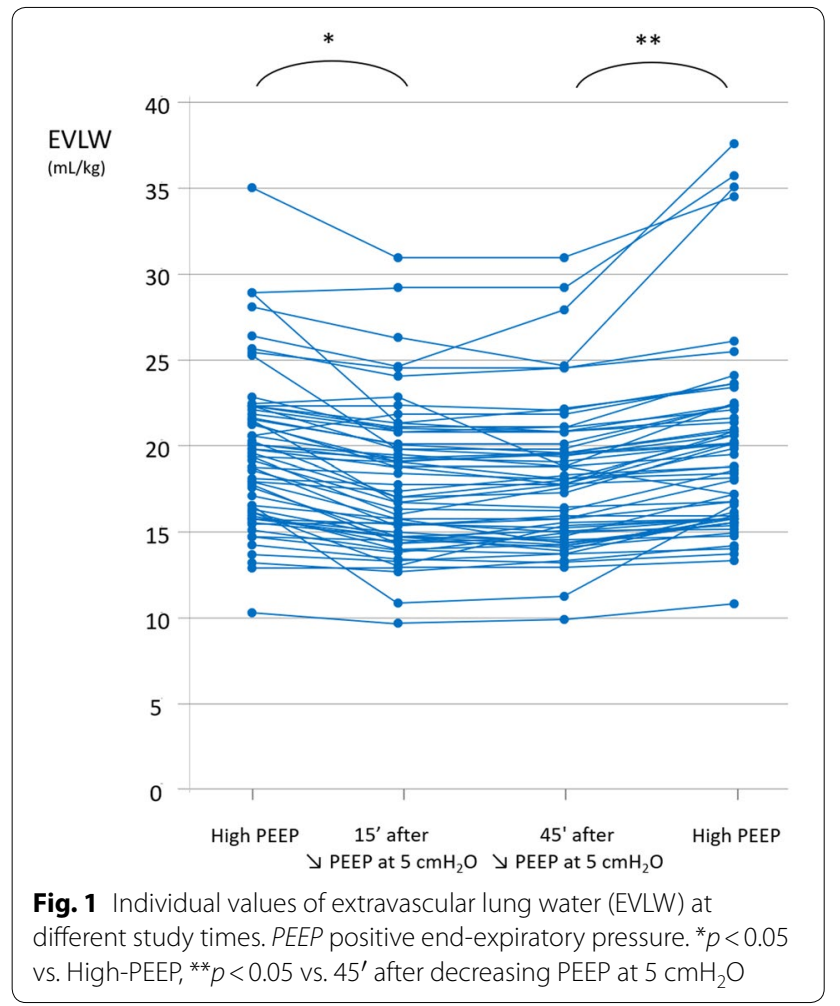

Table 3 Linear mixed model estimation on extravascular lung water changes adjusted by presence or absence of prone position and by changes in positive endexpiratory pressure, central venous pressure, and compliance of the respiratory system

\begin{tabular}{lrlrrr}
\hline & Value & Standard error & DF & $\boldsymbol{t}$ value & $\boldsymbol{p}$ value \\
\hline Intercept & 15.58 & 1.15 & 178 & 13.53 & \\
CVP & 0.15 & 0.07 & 178 & 2.16 & 0.03 \\
PEEP & 0.13 & 0.03 & 178 & 4.79 & $<0.01$ \\
Prone position & -0.78 & 1.56 & 57 & -0.5 & 0.62 \\
Crs & 0.61 & 1.21 & 57 & 0.5 & 0.62 \\
\hline
\end{tabular}

CVP central venous pressure, DF degrees of freedom, PEEP positive endexpiratory pressure, $C r$ r respiratory system compliance

was assessed by the PEEP-induced change in lung volume, the method that is today the best one for estimating recruitment/derecruitment at the bedside [36]. It was also the same in the whole population, when we defined derecruitment as a decrease in Crs. Moreover, neither the estimated derecruited lung volume nor the Crs changes were independently associated with EVLW changes at linear mixed model analysis.

Another argument against the explanation of EVLW changes by artefacts due to lung recruitment is that the changes in EVLW were observed rapidly both after 
reducing and increasing the PEEP level. Incrementing and decrementing PEEP have different impact on the time required to reach equilibrium in the respiratory system [47]. The fact that specular changes were observed after opposite PEEP changes strongly suggests that a haemodynamic mechanism may be a more plausible explanation for the observed results.

\section{Mechanisms of the PEEP-induced changes in EVLW}

Since the PEEP-induced changes in EVLW we observed were not due to artefacts in the TPTD estimation, one should consider that EVLW was really decreased when the PEEP level was reduced, and that this small and rapid change was reversible. Although of small amplitude, the EVLW changes were actually significant. Moreover, Fig. 1 shows well how EVLW changes were very consistent among patients. Also, we took the precaution to measure EVLW by averaging not three but five TPTD measurements, which enabled us to reliably detect small changes in EVLW [32].

Our results are in accordance with the previous studies which, amongst very discrepant ones, suggested that PEEP induces small increases in EVLW [3-8]. In theory, three mechanisms might explain why EVLW varies in the same direction as PEEP (Additional file 3: Figure S1). First, decreasing PEEP decreases CVP, which is the backward pressure of the drainage through the thoracic duct. This may happen by direct transmission of the intrathoracic pressure to the right atrial pressure, or as the result of the decrease in the right ventricular afterload. Although the changes in EVLW were of lower amplitude than those of CVP, the results of the linear mixed effect model make this pathophysiological hypothesis acceptable. Of note, even though it may increase CVP in ARDS patients $[48,49]$, prone position in our population was not an element influencing the relationship between CVP and EVLW.

The second mechanism which may explain why the PEEP decrease diminished EVLW is a decrease in the formation of lung water (Additional file 3: Figure S1). Indeed, the intrathoracic pressure is transmitted to the left atrium, such that when PEEP is decreased, the intramural pulmonary capillary pressure is decreased as well. It is well known that, on the opposite, augmenting PEEP increases the intramural pulmonary artery occlusion pressure [50]. We could not assess this mechanism, since we estimated neither the pulmonary capillary pressure nor the pulmonary artery occlusion pressure in our study.

The normal pulmonary lymphatic flow is estimated to be $8-9 \mathrm{~mL} / \mathrm{h}$ in humans [51]. Nevertheless, it has been reported that the pulmonary lymphatic flow could increase to tenfold, or even more, during ARDS [52]. Moreover, the estimation of pulmonary lymphatic flow in humans comes from animal studies, and it is much of an assumption that lymph flow is the same per kilogram of bodyweight in humans as in dogs [51]. Then, this is compatible with the amount of changes in EVLW we observed. The PEEP decrease led to a reduction of EVLW by $1.6 \pm 1.6 \mathrm{~mL} / \mathrm{kg}$, which was equivalent to roughly $100 \mathrm{~mL}$ of lung water accumulated in $15 \mathrm{~min}$, and vice versa when PEEP was re-increased. Nevertheless, since we did not directly measure the lymphatic flow and since the link between EVLW and CVP observed in our results was imperfect, we cannot exclude the contribution of other mechanisms.

In particular, it might be possible that part of the changes in EVLW we observed were related to changes in lung permeability, although this seems to be unlikely in such a short time. The decrease in PEEP was associated with a significant but slight decrease in PVPI, which reflects alveolo-capillary permeability. Nevertheless, this change was very small, and was not significantly reversed when PEEP was re-increased.

\section{Practical implications}

First, our findings show that TPTD is not flawed by the level of PEEP, as it has been previously suspected [53]. Second, our observation that increasing PEEP increases EVLW does not challenge the benefit of PEEP in ARDS. The increase in EVLW we report was small and might be easily counterbalanced by the potential benefits of PEEP such as increase in end-expiratory lung volume induced by recruitment, decrease in pulmonary shunt in recruiters and redistribution of alveolar fluid to extra-alveolar spaces [36]. Nevertheless, when using TPTD at the bedside [54], clinicians should be aware that changing PEEP might slightly change EVLW and that it is not due to a worsening of the disease or to the deleterious effects of some fluid administration.

\section{Limitations}

First, we only observed the short-term effects of PEEP. We judged it was ethically unacceptable to maintain these patients with ARDS at a low PEEP level for a long time. Moreover, it would have been impossible to avoid confounding events (changes in ventilatory setting and fluid administration or removal) over longer periods. Second, we estimated the derecruited volume during the PEEP decrease and not the recruited volume during the PEEP re-increase. Indeed, we speculated that derecruitment may occur faster than recruitment and be easier to detect [34]. Third, we directly measured the PEEP-induced changes in lung volume in 30 patients only, though it is the best method to estimate lung recruitment or derecruitment at the bedside. Estimating derecruitment through changes in Crs, as 
we did in the whole population, has many limitations [36]. Fourth, the number of saline boluses required for averaging EVLW measurements may have provoked fluid-induced changes in EVLW. However, the fact that EVLW decreased at the first study step indicates that this limitation probably had a very small impact. Fifth, because this was a human study, we could not directly measure the lymphatic flow, a procedure that could have strengthened our conclusions. Finally, we did not insert either a pulmonary artery catheter or an oesophageal balloon and thus could not estimate the hydrostatic lung filtration pressure and the transmural pressure. We thus cannot exclude that changing PEEP also changed the degree of pulmonary oedema formation.

\section{Conclusions}

In ARDS patients, changing the PEEP level induced parallel, small and reversible changes in EVLW. These changes were not due to an artefact of the TPTD technique and are likely due to the PEEP-induced changes in CVP.

\section{Supplementary information}

Supplementary information accompanies this paper at https://doi. org/10.1186/s13613-020-0644-2.

Additional file 1: Table S1. Previous literature regarding positive endexpiratory pressure effects on lung water in acute respiratory distress syndrome.

Additional file 2: Table S2. Mean difference of haemodynamic and respiratory variables for post hoc comparisons using Tukey HSD approach.

Additional file 3: Figure S1. Possible haemodynamic effects of positive end-expiratory pressure (PEEP) decrease on extravascular lung water (EVLW) levels, not taking into consideration possible artefactual effects related to the transpulmonary thermodilution (TPTD) method.

\section{Abbreviations}

ARDS: Acute respiratory distress syndrome; CVP: Central venous pressure; $\mathrm{Cl}$ : Cardiac index; Crs: Respiratory system compliance; EVLW: Extravascular lung water; $\mathrm{FiO}_{2}$ : Inspired oxygen fraction; $\mathrm{PaO}_{2}$ : Arterial oxygen partial pressure; $\mathrm{PaO}_{2} / \mathrm{FiO}_{2}$ : Arterial oxygen tension over inspired oxygen fraction ratio; PEEP: Positive end-expiratory pressure; Pplateau: Plateau pressure; PVPI: Pulmonary vascular permeability index; $\mathrm{SaO}_{2}$ : Arterial oxygen saturation; TPTD: Transpulmonary thermodilution; Vt: Tidal volume.

\section{Acknowledgements}

Not applicable.

\section{Authors' contributions}

$J \mathrm{LT}$ and $X \mathrm{M}$ conceived and designed the study. AB, CL, FG, IA and TT recruited the patients and collected the data. DA, FG, JLT and XM analysed and interpreted the data. GCA supervised the data interpretation. FG and XM drafted the report and all authors contributed to review it. All authors read and approved the final manuscript.

\section{Funding}

No funding.

\section{Availability of data and materials}

Individual, de-identified participant data are available from the corresponding author on reasonable request.

\section{Ethics approval and consent to participate}

Information and consent obtained for each patient.Name of the ethics committee that approved the study and the Committee's reference number: Comité pour la Protection des Personnes, Ile-de-France VII. Trial registration ID RCB: 2015-A01654-45. Registered 23 October 2015. The patients were included prospectively.

\section{Consent for publication}

Not applicable.

\section{Competing interests}

J.-L. Teboul and X. Monnet are members of the Medical Advisory Board of Pulsion Medical Systems. J.-L. Teboul and X. Monnet gave lectures for Masimo. The other authors have no conflict of interest to declare. No financial support.

\section{Author details}

${ }^{1}$ Service de médecine intensive - réanimation, Hôpitaux universitaires Paris-Saclay, Hôpital de Bicêtre, APHP, 78, rue du Général Leclerc, 94270 Le Kremlin-Bicêtre, France. ${ }^{2}$ Inserm UMR S_999, Univ Paris-Saclay, 78, rue du Général Leclerc, 94270 Le Kremlin-Bicêtre, France. ${ }^{3}$ Dipartimento di Medicina Traslazionale, Università del Piemonte Orientale, Via Solaroli 17, 28100 Novara, Italy.

Received: 7 June 2019 Accepted: 21 February 2020

Published online: 02 March 2020

\section{References}

1. Jozwiak M, Teboul J-L, Monnet X. Extravascular lung water in critical care: recent advances and clinical applications. Ann Intensive Care. 2015:5:38.

2. Kushimoto S, Endo T, Yamanouchi S, Sakamoto T, Ishikura H, Kitazawa $Y$, et al. Relationship between extravascular lung water and severity categories of acute respiratory distress syndrome by the Berlin definition. Crit Care. 2013;17:R132.

3. Toung T, Saharia P, Permutt S, Zuidema GD, Cameron JL. Aspiration pneumonia: beneficial and harmful effects of positive end-expiratory pressure. Surgery. 1977;82:279-83.

4. Carlile PV, Lowery DD, Gray BA. Effect of PEEP and type of injury on thermal-dye estimation of pulmonary edema. J Appl Physiol. 1985;1986(60):22-31.

5. Nieman GF, Bredenberg CE, Paskanik AM. Positive end-expiratory pressure accelerates lung water accumulation in high surface tension edema. Surgery. 1990;107:156-62.

6. Szakmany T, Heigl P, Molnar Z. Correlation between extravascular lung water and oxygenation in ALI/ARDS patients in septic shock: possible role in the development of atelectasis? Anaesth Intensive Care. 2004;32:196-201.

7. Krebs J, Pelosi P, Tsagogiorgas C, Alb M, Luecke T. Effects of positive end-expiratory pressure on respiratory function and hemodynamics in patients with acute respiratory failure with and without intra-abdominal hypertension: a pilot study. Crit Care. 2009;13:R160.

8. Wu X, Zheng R, Zhuang Z. Effect of transpulmonary pressure-guided positive end-expiratory pressure titration on lung injury in pigs with acute respiratory distress syndrome. J Clin Monit Comput. 2020;34:151-9.

9. Dunegan $L J$, Knight DC, Harken A, O'Conner N, Morgan A. Lung thermal volume in pulmonary edema: effect of positive end expiratory pressure. Ann Surg. 1975;181:809-12.

10. Russell JA, Hoeffel J, Murray JF. Effect of different levels of positive endexpiratory pressure on lung water content. J Appl Physiol. 1982;53:9-15.

11. Myers JC, Reilley TE, Vento JM, McDonald JS, Carey LC, Cloutier CT. Does compliance reflect oxygen delivery in porcine septic respiratory failure treated with positive end-expiratory pressure? Crit Care Med. 1987:15:38-40.

12. Borg T, Modig J. Intermittent and continuous positive-pressure ventilation in the prophylaxis of endotoxin-induced lung insufficiency. A study in pigs. Acta Anaesthesiol Scand. 1987;31:67-72. 
13. Myers JC, Reilley TE, Cloutier CT. Effect of positive end-expiratory pressure on extravascular lung water in porcine acute respiratory failure. Crit Care Med. 1988;16:52-4.

14. Corbridge TC, Wood LD, Crawford GP, Chudoba MJ, Yanos J, Sznajder Jl. Adverse effects of large tidal volume and low PEEP in canine acid aspiration. Am Rev Respir Dis. 1990;142:311-5.

15. Colmenero-Ruiz M, Fernández-Mondéjar E, Fernández-Sacristán MA, Rivera-Fernández R, Vazquez-Mata G. PEEP and low tidal volume ventilation reduce lung water in porcine pulmonary edema. Am J Respir Crit Care Med. 1997;155:964-70.

16. Ruiz-Bailén M, Fernández-Mondéjar E, Hurtado-Ruiz B, Colmenero-Ruiz M, Rivera-Fernández R, Guerrero-López F, et al. Immediate application of positive-end expiratory pressure is more effective than delayed positiveend expiratory pressure to reduce extravascular lung water. Crit Care Med. 1999;27:380-4.

17. Luecke T, Roth $H$, Herrmann P, Joachim A, Weisser G, Pelosi P, et al. PEEP decreases atelectasis and extravascular lung water but not lung tissue volume in surfactant-washout lung injury. Intensive Care Med. 2003;29:2026-33.

18. Hopewell PC. Failure of positive end-expiratory pressure to decrease lung water content in alloxan-induced pulmonary edema. Am Rev Respir Dis. 1979;120:813-9.

19. Miller WC, Rice DL, Unger KM, Bradley BL. Effect of PEEP on lung water content in experimental noncardiogenic pulmonary edema. Crit Care Med. 1981:9:7-9

20. Peitzman AB, Corbett WA, Shires GT, Lynch NJ, Shires GT. The effect of increasing end-expiratory pressure on extravascular lung water. Surgery. 1981;90:439-45.

21. Peitzman AB, Shires GT, IIIner H, Shires GT. Pulmonary acid injury: effects of positive end-expiratory pressure and crystalloid vs colloid fluid resuscitation. Arch Surg. 1960;1982(117):662-8.

22. Luce JM, Robertson HT, Huang T, Colley PS, Gronka R, Nessly ML, et al. The effects of expiratory positive airway pressure on the resolution of oleic acidinduced lung injury in dogs. Am Rev Respir Dis. 1982;125:716-22.

23. Saul GM, Feeley TW, Mihm FG. Effect of graded administration of PEEP on lung water in noncardiogenic pulmonary edema. Crit Care Med. 1982;10:667-9.

24. Luce JM, Huang TW, Robertson HT, Colley PS, Gronka R, Nessly ML, et al. The effects of prophylactic expiratory positive airway pressure on the resolution of oleic acid-induced lung injury in dogs. Ann Surg. 1983;197:327-36.

25. Slutsky RA. Reduction in pulmonary blood volume during positive endexpiratory pressure. J Surg Res. 1983;35:181-7.

26. Helbert C, Paskanik A, Bredenberg CE. Effect of positive end-expiratory pressure on lung water in pulmonary edema caused by increased membrane permeability. Ann Thorac Surg. 1983;36:42-8.

27. Malo J, Ali J, Wood LD. How does positive end-expiratory pressure reduce intrapulmonary shunt in canine pulmonary edema? J Appl Physiol. 1984;57:1002-10.

28. Toth I, Leiner T, Mikor A, Szakmany T, Bogar L, Molnar Z. Hemodynamic and respiratory changes during lung recruitment and descending optimal positive end-expiratory pressure titration in patients with acute respiratory distress syndrome. Crit Care Med. 2007;35:787-93.

29. ARDS Definition Task Force, Ranieri VM, Rubenfeld GD, Thompson BT, Ferguson ND, Caldwell E, et al. Acute respiratory distress syndrome: the Berlin Definition. JAMA. 2012;307:2526-33.

30. Dufour N, Delville M, Teboul J-L, Camous L, Favier du Noyer A, Richard C, et al. Transpulmonary thermodilution measurements are not affected by continuous veno-venous hemofiltration at high blood pump flow. Intensive Care Med. 2012;38:1162-8

31. Sakka SG, Hanusch T, Thuemer O, Wegscheider K. The influence of venovenous renal replacement therapy on measurements by the transpulmonary thermodilution technique. Anesth Analg. 2007;105:1079-82 (table of contents).

32. Monnet $X$, Persichini R, Ktari M, Jozwiak M, Richard C, Teboul J-L. Precision of the transpulmonary thermodilution measurements. Crit Care. 2011;15:R204.

33. Monnet $X$, Teboul J-L. Transpulmonary thermodilution: advantages and limits. Crit Care. 2017;21:147.

34. Chen L, Chen G-Q, Shore K, Shklar O, Martins C, Devenyi B, et al. Implementing a bedside assessment of respiratory mechanics in patients with acute respiratory distress syndrome. Crit Care. 2017;21:84.
35. Dellamonica J, Lerolle N, Sargentini C, Beduneau G, Di Marco F, Mercat A et al. PEEP-induced changes in lung volume in acute respiratory distress syndrome. Two methods to estimate alveolar recruitment. Intensive Care Med. 2011;37:1595-604.

36. Sahetya SK, Goligher EC, Brower RG. Fifty years of research in ARDS. Setting positive end-expiratory pressure in acute respiratory distress syndrome. Am J Respir Crit Care Med. 2017;195:1429-38.

37. Rhodes A, Evans LE, Alhazzani W, Levy MM, Antonelli M, Ferrer R, et al. Surviving sepsis campaign: international guidelines for management of sepsis and septic shock: 2016. Intensive Care Med. 2017;43:304-77.

38. Jozwiak M, Silva S, Persichini R, Anguel N, Osman D, Richard C, et al. Extravascular lung water is an independent prognostic factor in patients with acute respiratory distress syndrome. Crit Care Med. 2013:41:472-80.

39. Tagami T, Kushimoto S, Yamamoto Y, Atsumi T, Tosa R, Matsuda K, et al. Validation of extravascular lung water measurement by single transpulmonary thermodilution: human autopsy study. Crit Care. 2010;14:R162.

40. Dres M, Teboul J-L, Guerin L, Anguel N, Amilien V, Clair M-P, et al. Transpulmonary thermodilution enables to detect small short-term changes in extravascular lung water induced by a bronchoalveolar lavage. Crit Care Med. 2014;42:1869-73.

41. Cordemans C, De Laet I, Van Regenmortel N, Schoonheydt K, Dits H, Huber W, et al. Fluid management in critically ill patients: the role of extravascular lung water, abdominal hypertension, capillary leak, and fluid balance. Ann Intensive Care. 2012;2:S1.

42. Huber W, Höllthaler J, Schuster T, Umgelter A, Franzen M, Saugel B, et al. Association between different indexations of extravascular lung water (EVLW) and $\mathrm{PaO}_{2} / \mathrm{FiO}_{2}$ : a two-center study in 231 patients. PLoS ONE. 2014;9:e103854

43. Martin GS, Eaton S, Mealer M, Moss M. Extravascular lung water in patients with severe sepsis: a prospective cohort study. Crit Care. 2005;9:R74-82.

44. Mallat J, Pepy F, Lemyze M, Barrailler S, Gasan G, Tronchon L, et al. Extravascular lung water indexed or not to predicted body weight is a predictor of mortality in septic shock patients. J Crit Care. 2012;27:376-83.

45. Tagami T, Nakamura T, Kushimoto S, Tosa R, Watanabe A, Kaneko T, et al. Early-phase changes of extravascular lung water index as a prognostic indicator in acute respiratory distress syndrome patients. Ann Intensive Care. 2014:4:27.

46. Fan E, Brodie D, Slutsky AS. Acute respiratory distress syndrome: advances in diagnosis and treatment. JAMA. 2018;319:698-710.

47. Chiumello D, Coppola S, Froio S, Mietto C, Brazzi L, Carlesso E, et al. Time to reach a new steady state after changes of positive end expiratory pressure. Intensive Care Med. 2013;39:1377-85.

48. Pelosi P, Bottino N, Chiumello D, Caironi P, Panigada M, Gamberoni C, et al. Sigh in supine and prone position during acute respiratory distress syndrome. Am J Respir Crit Care Med. 2003;167:521-7.

49. Jozwiak M, Teboul J-L, Anguel N, Persichini R, Silva S, Chemla D, et al. Beneficial hemodynamic effects of prone positioning in patients with acute respiratory distress syndrome. Am J Respir Crit Care Med. 2013;188:1428-33.

50. Teboul JL, Pinsky MR, Mercat A, Anguel N, Bernardin G, Achard JM, et al. Estimating cardiac filling pressure in mechanically ventilated patients with hyperinflation. Crit Care Med. 2000;28:3631-6.

51. Hedenstierna G, Lattuada M. Lymphatics and lymph in acute lung injury. Curr Opin Crit Care. 2008;14:31-6.

52. Frostell $\mathrm{C}$, Blomqvist $\mathrm{H}$, Wickerts $\mathrm{CJ}$. Effects of PEEP on extravascular lung water and central blood volume in the dog. Acta Anaesthesiol Scand. 1987;31:711-6.

53. Effros RM, Pornsuriyasak P, Porszasz J, Casaburi R. Indicator dilution measurements of extravascular lung water: basic assumptions and observations. Am J Physiol Lung Cell Mol Physiol. 2008;294:L1023-31.

54. Cecconi M, De Backer D, Antonelli M, Beale R, Bakker J, Hofer C, et al. Consensus on circulatory shock and hemodynamic monitoring. Task force of the European Society of Intensive Care Medicine. Intensive Care Med. 2014;40:1795-815.

\section{Publisher's Note}

Springer Nature remains neutral with regard to jurisdictional claims in published maps and institutional affiliations. 